\title{
CAD Based Analysis for Feasibility of Design of an Amphibious Vehicle for Recreation
}

\author{
Debashis Majumder, Anirban Chowdhury
}

\begin{abstract}
An amphibious vehicle is the vehicle that allows occupants to travel on both land and water. Since an amphibious vehicle must inherently possess both land and water capabilities, design of the vehicle should not compromise the requirements for a good boat as well as a good land vehicle. Although, amphibious vehicles were used for different purposes, still there is no mention of application of amphibious vehicle in recreational purposes such as beach riding, surfing on water and travel within Science Parks. Further, with depletion of fossil fuel and for all the negative effect on marine life. Hence, an attempt is made to design an electric amphibious vehicle for recreational purpose and utilize for travel within Science \& Technology Park. A conceptual design was worked out and it is matched with visual aspects of amphibian animal like duck. A CAD model was prepared with structural details. Structural strength was analyzed using ANSYS software. CFD analysis was conducted for calculating drag and surface shear stress and buoyancy was calculated. Thus it gives a practical approach to construction of an amphibious vehicle for recreational purpose. The results of the CAD analysis shows that the stress on the Frame was within acceptable limit and the buoyancy conditions are fulfilled. It also suggest for a maximum speed of 40kmph on water. As look and feel of the vehicle inspired from duck beak, it gives expression of amphibian characteristics along with sporty look. Thus, the conceptual vehicle is suitable for use on land and on water inside Science \& Technology park.
\end{abstract}

Keywords: Amphibious Vehicle, CAD Model, CFD Analysis, Design , Electric Vehicle,

\section{INTRODUCTION}

There were occasional examples of use of amphibious nature of vehicle. Sometime it was bicycle some time it was car etc. These were very few in number and in a specific area. Vehicles such as Amphicar which was built by Quandt group in the 60s was a remarkable feat in amphibious vehicle production and an early inspiration. Although this rear wheeled wonder was soon out of production due to cost issues and several parts made of steel which was prone to rust and required high maintenance, it had various design aspects like high ground clearance for better maneuverability and

Manuscript received on August 13, 2021.

Revised Manuscript received on August 17, 2021.

Manuscript published on August 30, 2021.

* Correspondence Author

Debashis Majumder*, Professor \& Coordinator of Transportation Design in School of Design, UPES, Dehradun (Uttarakhand), India. Email: mejda1166@gmail.com

Dr. Anirban Chowdhury, Faculty \& Head of UX \& IXD and R \& D Coordinator to School of Design, University of Petroleum and Energy Studies, Dehradun (Uttarakhand), India. Email: Chowdhuryanirban14@gmail.com

(c) The Authors. Published by Blue Eyes Intelligence Engineering and Sciences Publication (BEIESP). This is an open access article under the CC BY-NC-ND license (http://creativecommons.org/licenses/by-nc-nd/4.0/) traction control on land. Also a large bulge around the engine provided better hydrodynamic as well as ground effect [1].

Many films like Pontiac Moon and a 60s Pepsi Commercial featuring Amphibian vehicles at high speed on water also motivated us to build a similar recreational multi utility vehicle. Gibbs Aquada is also a prototype design which incorporates a thrust jet propulsion technology made high speed mobility on water, an achievable feat. Its design aspect can be an employed in our amphibian vehicle for high thrust and speed allowances in water [2].

\section{LITERATURE REVIEW}

\section{A. Amphibious human powered cycles}

These are some independently made human powered cycles having capability to move both on land and water. A very primitive design of a human powered bicycle made by Md. Saidullah, an innovator from Bihar incorporates four air filled floats for achieving buoyancy and propulsion is done using fins attached to the spokes of the wheels. It was also documented by Discovery Channel.

\section{B. Amphibious trucks and artillery vehicles}

During the World War II, the US military used DUKW trucks which had a 6X6 wheel drive. Germany's Schwimmwagen and Russia's GAZ 46 were also some similar primitive amphibious truck design used in the war [4].

The Vietnam war which spanned from 1955 to 1975 also saw many unique amphibian military-based carrier designs. The British developed a 6X6 cargo carrier named Alvis Stalwart in the 60s capable of achieving 6 knots with the help of water-jet propulsion technology. Germans developed the M3 Amphibious rig capable of carrying multiple army personnel along with heavy vehicles and cargos.

A very unique design was seen in the British design made in the wake of World War II named Sherman (after the Civil war general William Sherman) which was also dubbed as "Duplex Drive" due to the fact that it consisted of rubberized screen which was opened by the soldiers before entering the water to provide additional buoyancy. It had a propeller based propulsion system. The design was flawed as it was useless when afloat due to the covering of the guns by the screen [4].

\section{Hovercraft based vehicles}

These are air cushion-based vehicles which are also reimagined on the big screen in the flicks such as the 2002 James Bond flick Die Another Day.

Published By:

Blue Eyes Intelligence Engineering and Sciences Publication 
It is based on the principle of levitation based on an air cushion of low pressure air between vehicle base and the ground. They have an advantage of transition from land to water or vice versa at speed and even go as high as $150 \mathrm{mph}$ on water! It sure has a few drawbacks which include demand for a levelled terrain and high fuel consumption [5].

\section{Commercial Amphibious vehicles}

Many designs of AVs are based on World War II based amphibian vehicle that are now used for recreation and tourist sight- seeing purposes. They are used in places like water bodies of Venice etc. Many concepts and prototypes like the Rinspeed Squaba and Gibbs Aquada have been produced for a limited consumer market [3].

Many people have tried to modify and customize their personal wagons into recreational family type amphibian vehicle. Bert Sandlin from New Orleans made a home-made $\mathrm{AV}$ at his garage which is cheap and can hit the war at 40 $\mathrm{mph}$. It has fiberglass and Styrofoam reinforcements for extra buoyancy [6].

\section{OBJECTIVE OF THE STUDY}

A. To develop a concept an amphibious vehicle AV (for travel within Science \& Technology Park) by taking inspiration from amphibious animal

B. To ensure the feasibility of the developed concept using CAD software (through static stress analysis and drag

\section{METHODOLOGY}

Need based conceptual design of few AVs were worked out and matched with visual aspects of vehicle for recreational purpose. A CAD model was prepared with structural details. Structural strength was analyzed with ANSYS software. The CFD analysis was conducted for calculating drag and surface shear stress. The buoyancy of the CAD model of AV was calculated. Thus it gives a practical approach to construction of an amphibious vehicle for recreational sports [10] [11].

\section{A. Steps of Design Process}

- Ideation

- User Survey (Secondary Research)

- Inspiration / Mood Board creation

- CAD Model Preparation in CATIA V5

- Validation of body Design

- Component selection

- Weight finalization

- Dimension Finalization

- Buoyancy Calculation

- Chassis design by FE Analysis

- CFD Analysis of Body for body design analysis)

- Conceptual Design

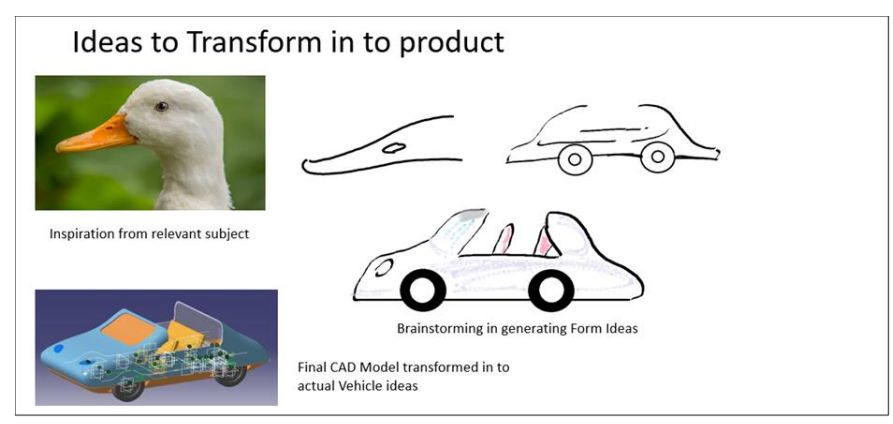

Fig. 1 Concept generation from Mood Board considering Bio inspiration (Duck).

\section{B. Development of CAD Model.}

Based on Bio- inspired concept, a CAD model was developed and detail prototyping was done. Please find the CAD model of the AV for recreation (at Science \& Technology Park) in Fig. 2.

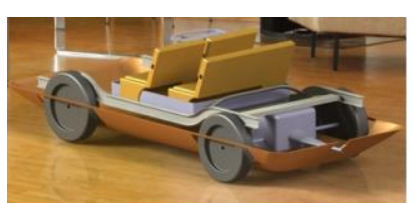

A

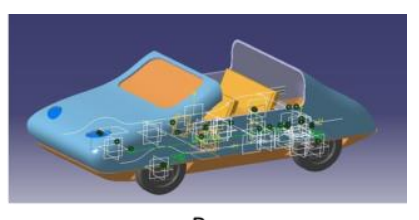

B
Fig. 2. CAD models for the designed vehicle (A: Interior parts of the AV, B: Exterior of the AV).

The dimensions of the vehicle are decided by taking inspiration from the dimensions of existing electric land vehicles such as- Nissan Leaf and Chevrolet Bolt. The ladder type chassis is modelled as the first step and the followed by mechanical components such as the suspension, differential, motors, seats and finally the body (See Table 1).

Table 1. Dimensions for AV CAD prototype

\begin{tabular}{|c|c|}
\hline Part Name & Dimension (mm) \\
\hline Wheelbase & 2700 \\
\hline Total height of the car & 1900 \\
\hline Ground Clearance & 200 \\
\hline Body length & 5200 \\
\hline Body width & 2200 \\
\hline Wheel diameter & 550 \\
\hline Hull beam & 2240 \\
\hline Hull LOA & 5350 \\
\hline
\end{tabular}

\section{DESIGN OF AN AMPHIBIOUS VEHICLE FOR RECREATION}

The AV for recreational use is getting popular. In many countries, several forms of AVs are found to be used. Studies have been made to design a new AV design for recreational purposes. Here attempt has been made to evaluate and optimize material and optimise feasibility by using CAD software. 
For modeling Catia and Fusion 360 is used and for FE analysis, software like Ansys is used to evaluate stress on chassis and fluid flow pressure on body by using Ansys. This will optimize the design. Similar approach may be taken for design of other AVs for recreational use.

Components for electric AV was planned. These are battery, motor for wheels, hull, frame, body, tires and water jet propulsion system. As AVs will roll on land and dive in water, rigid expanded Polyurethane was chosen for vehicle body design and 5052 is an Aluminum alloy, primarily alloyed with magnesium and chromium for the body [12].

Followings are the major elements of the Amphibious Vehicle:

\section{A. The Hull}

The hull of a wheeled amphibian is the enclosure which contains the crew compartment, cargo compartment, engine compartment, and numerous other vehicle components. The amphibian hull differs fundamentally from the body of other military automotive assemblies in that it must satisfy certain marine design criteria. Specifically, it must exhibit the required stability and buoyancy characteristics as well as have a configuration that will result in an acceptable speed-power relationship for waterborne operations. In summary, the purpose of the amphibian hull is twofold-it serves as a boat hull and as a truck body [7].

An Inboard flange can be used for the assembly of the body and the hull and the sealing is done by applying epoxy resin on the hull.

\section{B. The Propulsion System}

There are two categories in which amphibious vehicles are divided on the basis of how they are propelled in water- how they are propelled on land. Here much of the system remains common for both. It contains system that can travel on a wide number of terrains including on water. These are different mechanism used in this type of vehicles and use of tracks, screw mechanisms, water jet propulsion and even regular propellers [8].

In this study, the propulsion system adopted was based on existing propulsion system for small electric vehicle in other applications. The propulsion system for water will be jet based propulsion. However, the design is subjected to future alterations with jet and other rotor based hybrid propulsion or normal rotor based propulsion system as per the cost allowances [13].

\section{Power Train (EV)}

Apart from being environment friendly and having a rapidly growing infrastructure - electric technology provides a wider range of torque, quite operation, cheaper running costs and minimal maintenance as compared to IC engines. Maneuvering the vehicle and getting it on and out of water is also a big challenge according to most hobbyists. It also provides green technology to support environment. As they move in water, the fossil fuel effect aquatic life also [9] [10].

\section{ELECTRICAL COMPONENTS OF AV}

Electrical components were decided by considering existing electric vehicle called GM 'Bolt'. Please refer Table 2 for details and specifications of the electrical components.
Table 2: Components and specifications of electric AV

\begin{tabular}{|c|c|c|}
\hline Component selected & Specification & Remarks \\
\hline Battery & $\begin{array}{l}\text { LG } 40 \text { Battery } \\
\text { module pack, } \\
60 \mathrm{KWh}\end{array}$ & Same as GM Bolt \\
\hline Motor for wheels & $\begin{array}{l}100 \mathrm{KW} \\
\text { synchronous } \\
\text { motor by } \\
\text { Siemens (model } \\
\text { SIVETEC MRS) }\end{array}$ & $\begin{array}{l}\text { Also used in } \\
\text { Volvo S60 } \\
\text { Hybrid }\end{array}$ \\
\hline Hull & $\begin{array}{l}\text { Flat bottomed } \\
\text { glass fiber } \\
\text { reinforced plastic } \\
\text { hull }\end{array}$ & \\
\hline Frame & $\begin{array}{l}\text { Ladder type frame } \\
\text { made by Carbon } \\
\text { steel }\end{array}$ & \\
\hline Body & $\begin{array}{l}\text { Body made out of } \\
5052 \text { Aluminum } \\
\text { alloy }\end{array}$ & $\begin{array}{l}5052 \text { is an } \\
\text { Aluminum } \\
\text { alloy, primarily } \\
\text { alloyed with } \\
\text { magnesium and } \\
\text { chromium. }\end{array}$ \\
\hline Tires & 20in Michelin tires & \\
\hline $\begin{array}{l}\text { Water jet } \\
\text { propulsion system }\end{array}$ & $\begin{array}{l}\text { Berkeley Jet } \\
\text { Drive Model } \\
\text { 12JC }\end{array}$ & $\begin{array}{l}\text { Made out of high } \\
\text { strength } \\
\text { aluminum } \\
\text { alloy }\end{array}$ \\
\hline $\begin{array}{l}\text { Rigid } \\
\text { expanded } \\
\text { polyurethane }\end{array}$ & CORAFOAM® & $\begin{array}{l}\text { comes as two } \\
\text { liquids to be } \\
\text { mixed and } \\
\text { poured in }\end{array}$ \\
\hline
\end{tabular}

The powertrain of the vehicle was decided based on the land based electric vehicle like Nissan Leaf or Chevrolet Bolt. The project is solely an electric vehicle (EV) with a proper assembly of motors driven by a central battery pack and other necessary modules fixed on board.

\section{RESULTS \& DISCUSSION}

\section{A. Static Stress Calculation on Frame}

The results of stress analysis of the Frame using new boundary conditions are found to be safe and within limit. Here in static analysis, a typical ladder frame chassis is considered. The different load considerations are taken for analysis (land and water). The chassis is designed analytically by varying materials in rectangular cross section of beam [14].

There are various steps that are to be followed in analyzing a component structurally. Here the Gross weight of body is considered to be $862.5 \mathrm{~kg}$. Here the factor safety is taken as 4 and von misses stress is within limit so the design is acceptable.

The main steps are:-

1. Geometric model design

2. Mesh generation

3. Fixed supports

4. Application of loads

5. Evaluating result

Published By:

Blue Eyes Intelligence Engineering and Sciences Publication

(C) Copyright: All rights reserved. 
The stress plots are shown in Fig. 3

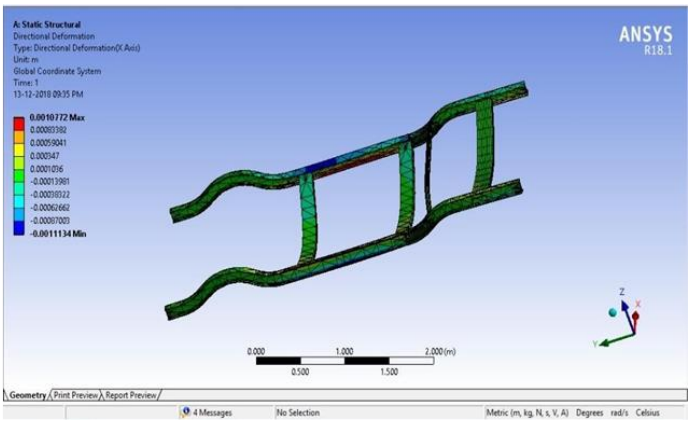

Fig. 3. Stress Analysis of Frame Deformation $0.8 \mathrm{~m}$. m. (distribution of load in water).

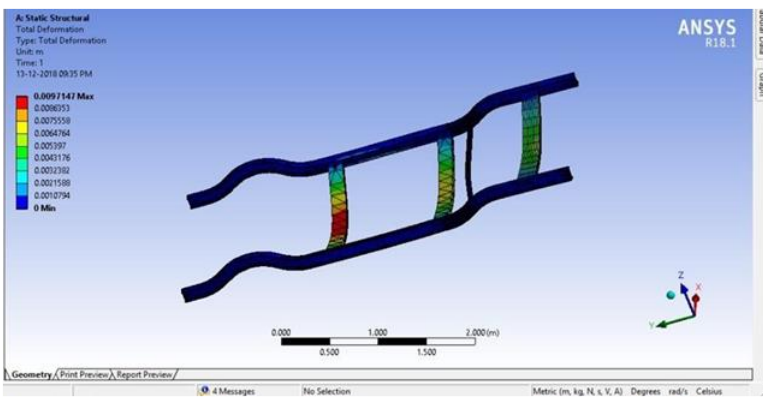

Fig.4. Total Deformation 8.6 millimeter (distribution of load in land).

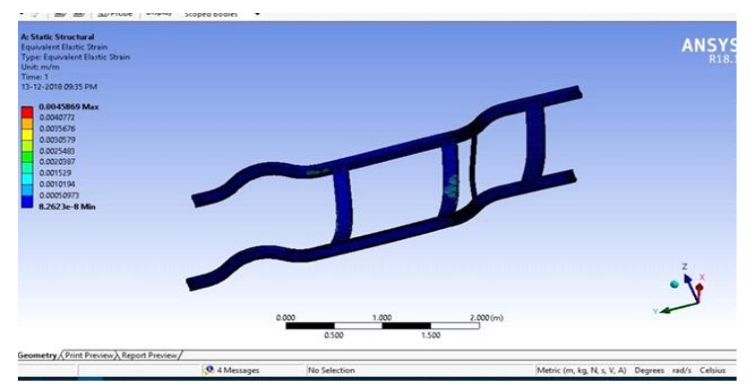

Fig. 5 Equivalent Elastic strain of the frame is 0.00050973

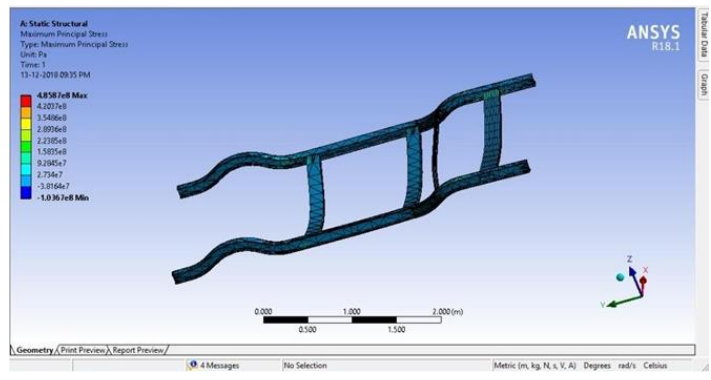

Fig.6. Maximum Principal Stress 485.87 MPa.

Table. 3 Properties of Material

\begin{tabular}{|l|c|}
\hline \multicolumn{1}{|c|}{ Property } & HSLA Steel \\
\hline Mass density (Kg/m3) & 7850 \\
\hline Yield strength (Mpa) & 552 \\
\hline Ultimate tensile strength (Mpa) & 630 \\
\hline Poisons ratio & 0.3 \\
\hline Shear Modulus (Gpa) & 76.9 \\
\hline Young's Modulus (Gpa) & 200 \\
\hline
\end{tabular}

\# This Table is adapted from [18]
HSLA steels have yield strengths greater than $550 \mathrm{MPa}$

Acicular ferrite (low-carbon bainite) steels, which are low-carbon (less than $0.05 \% \mathrm{C}$ ) steels with an excellent combination of high yield strengths, (as high as $690 \mathrm{MPa}$, or 100 ksi) weldability, formability, and good toughness[15][16] [17].

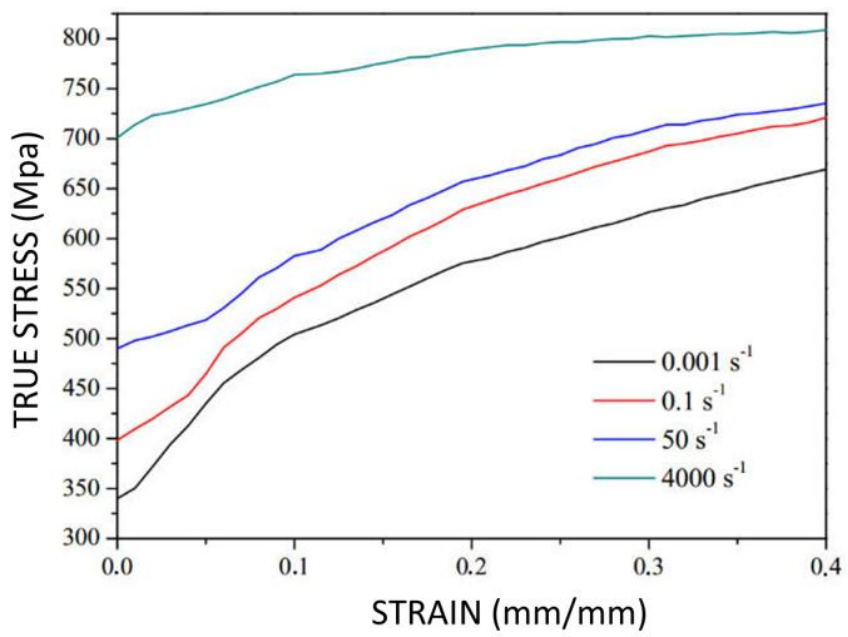

Table 4. Stress Strain Curve of HSLA Steel (this graph is adopted from [26]).

B. The CFD Analysis of the Hull

- Calculation of viscous drag:

For calculating viscous drag due to hull we are using the following formulas:

$\operatorname{Rv}($ viscous drag $)=0.5 x($ density of water $) \times($ speed of vehicle $)^{\wedge} 2 \mathrm{x}$ (surface area of the hull) $\mathrm{x}$ (coefficient of friction) $\mathrm{Cf}($ coefficient of friction $)=0.075 /\{(\log$ Rnum $)-2\} \wedge 2$ Rnum (Reynold's No.) = [(speed of the vehicle) $\mathrm{x}$ (waterline length)] / (kinematic viscosity of water)

Data: Speed of the vehicle $=40 \mathrm{kmph}$

Waterline length $=5141 \mathrm{~mm}$

Surface area of the hull $=1.38 \mathrm{e}+7 \mathrm{~mm}^{\wedge} 2 \mathrm{v}$ (kinematic viscosity $)=8.9 \mathrm{e}-7 \mathrm{~m}^{\wedge} 2 \mathrm{~s}$ Density of water $=1000 \mathrm{kgm}-3$

$\mathrm{R}_{\text {num }}=6.47 \mathrm{e}+7 . \mathrm{C}_{\mathrm{f}}=0.00222$

$\mathrm{R}_{\mathrm{v}}=1921.5 \mathrm{~N}$ or $1.92 \mathrm{kN}$.

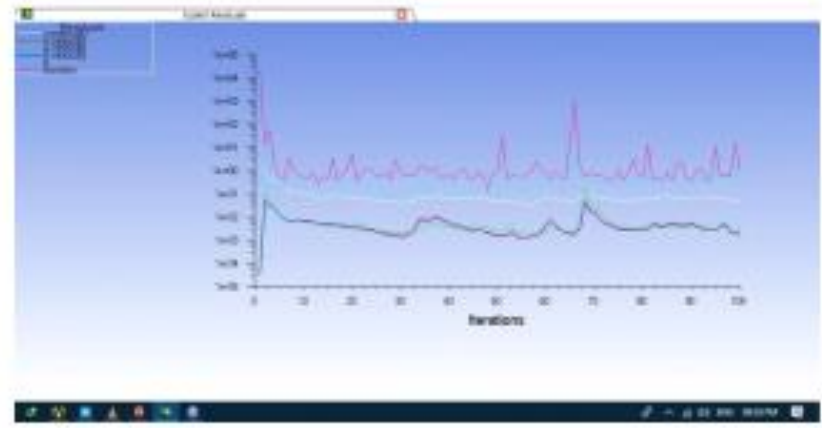

Fig. 7. CFD Analysis on the model done in Ansys 18.1

Published By:

Blue Eyes Intelligence Engineering and Sciences Publication

(C) Copyright: All rights reserved.

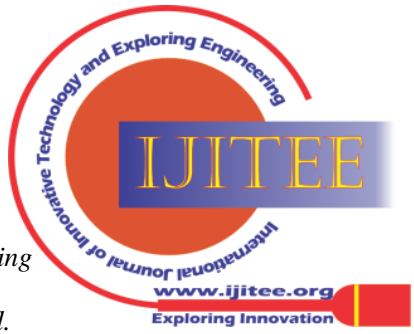




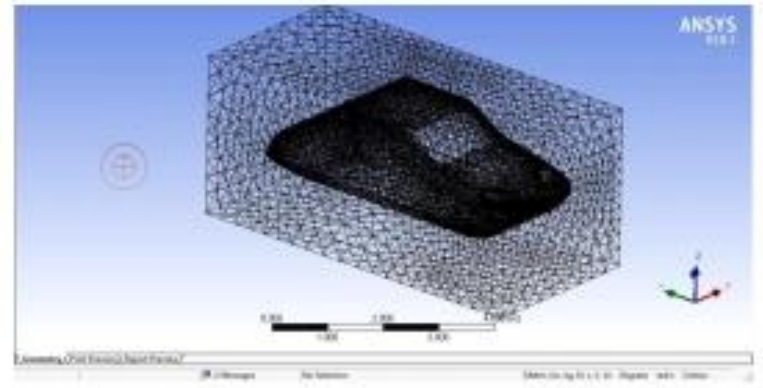

Fig. 8. Mesh model done in Ansys 18.1

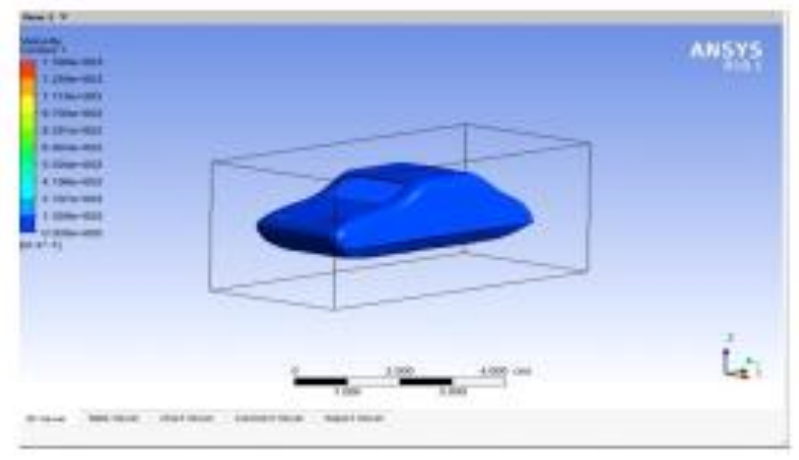

Fig. 9. Velocity Contour

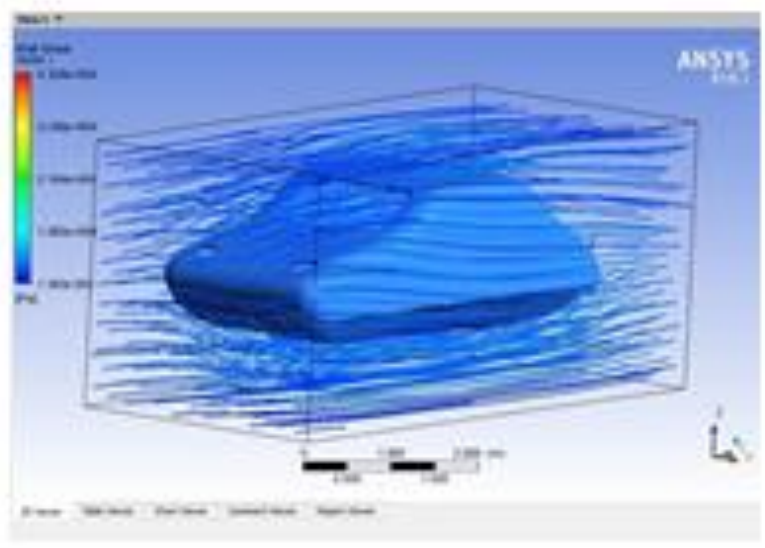

Fig. 10. Wall Shear Vector

Wall Shear vector is within acceptable range.

\section{The submerged hull volume}

Volume is calculated using Fusion 360 software.

The buoyancy of the amphibious hybrid vehicle is depending on the parameter of the bottom hull body to keep it afloat every time. Based on the Archimedes principle, the weight of the floating object is equal to the volume of water displaced [18][19][20].

To calculate the appropriate water line length of our hull, we used the following approach:

Slicing the hull an arbitrary LWL and calculating the lower part's volume. The obtained value is inserted in the formula:

$\mathrm{F}_{\mathrm{b}}=\mathrm{p}_{\mathrm{w}} \mathrm{g} \mathrm{V}$ (Buoyancy Formula)

$\mathrm{F}_{\mathrm{b}}=997 \mathrm{~kg} / \mathrm{m}^{3} * 9.81 \mathrm{~kg} \mathrm{~m} / \mathrm{s} 2 * 0.205 \mathrm{~m} 3$ (using Fusion 360 software)

$\mathrm{F}_{\mathrm{b}}=19.2 \mathrm{KN}$

${ }^{*} \mathrm{p}_{\mathrm{w}}$ value at $25^{\circ} \mathrm{C}$ was considered

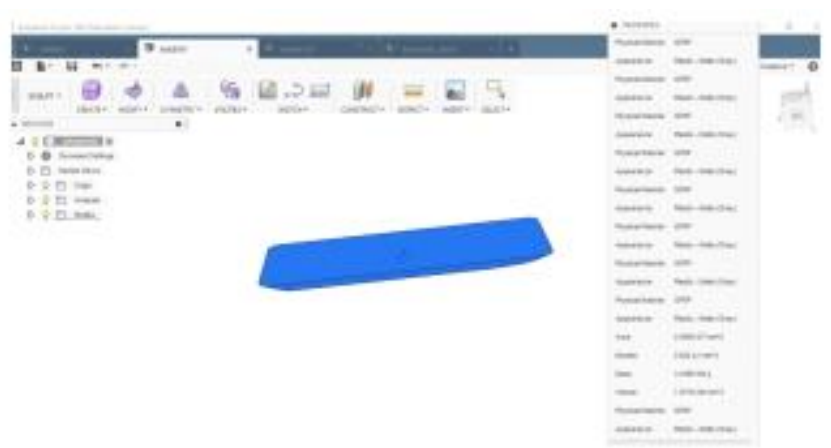

Fig. 8. Floating Hull design done using Fusion 360.

The submerged hull volume is calculated using Fusion 360 software. The obtained values should be close to the values of mog as, pwVg = mog. Necessary changes to the hull dimensions are made if the values differ for Floating condition.

Waterline length $=5141 \mathrm{~mm}$

Hull draft $=250 \mathrm{~mm}$

\section{Range calculation}

For calculating the range till which the battery can work is calculated by using the following approach [21] [22] [23]

No. of modules $=40$

Voltage of each module $=3 \mathrm{~V}$, Total battery voltage $=120 \mathrm{~V}$

Current drawn= 60 Amp at $40 \mathrm{kmph}$,

Formula used here is: I*V/Speed= Range

Range at $40 \mathrm{kmph}=360 \mathrm{Wh} / \mathrm{m}$.

Also, Range $=$ Total battery capacity/ (Wh per mile usage) therefore, at 20mph Range $=155.67$ miles $=270 \mathrm{Km}$ Similarly, at $50 \mathrm{mph}$ range $=255 \mathrm{Km}$

It has to be noted that the actual value maybe upto 55\% to $79 \%$ of ideal value in the case of a Lithium ion battery.

\section{CONCLUSION}

The conceptual development of amphibious vehicle for recreational sports in present day context was explored. The various aspects of user interface and technical feasibility was studied and the design concept was done considering psychological aspect of user mind. The amphibian creature like duck was taken in to consideration as an inspiration to design AV. The form feature of beak of duck was used to come out with interesting form of vehicle. The unique visual design aspect creates invitation and interest for using the amphibious vehicle for recreational purpose. This can popularize amphibious vehicle again in market and it unique advantages can be used for benefit of mankind.

In this study, the feasibility of making amphibious vehicle is tried out from the above mentioned concept and it's actual manufacturing constraints are considered. Apart from aesthetic and innovative approach to design, the engineering aspect of structural strength, fluid dynamics and buoyancy are also calculated. The strength of body structure is appropriate to move on land and on water.

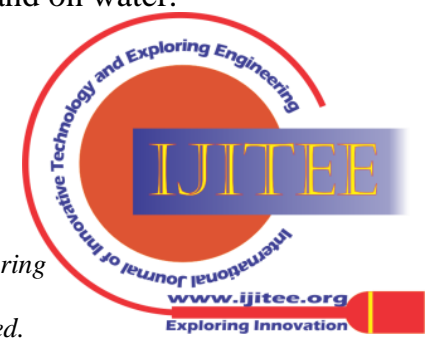


The designed vehicle is suitable for recreation on water side and it can be implemented for recreational purpose in pre-planned 'Science Park' where it can run on water as well as on land. It also does not pollute environment. So in many places like jungle and nature parks, it will be very appropriate.

\section{FUTURE SCOPE OF THE VEHICLE}

Amphibious vehicle can be used for many innovative application in present day society. The actual use is limitless. However, the current vehicle might need further aesthetic improvement and appropriate positioning in market. The actual vehicle development and testing will reinforce the feasibility of mass production and cost control. Detail manufacturing and material selection can be done in future to make it easier for mass production [24] [25].

\section{ACKNOWLEDGMENT}

The project work carried out and helped by students of ADE, Mechanical Engineering department of University (UPES). I acknowledge the support of Mr. Utkarsh Seth (R160216113), Mr. Subodh Srivastava (R160216108) and Mr.Vaibhav Kumar (R160216115).

\section{REFERENCES}

1. Roach CD. Design of Wheeled Amphibians. 'ARMY TRANSPORTATION RESEARCH COMMAND FORT EUSTIS VA'; 1960 Apr 21.

2. Hajare, P. M. S., et al. "A REVIEW ON DESIGN AND ANALYSIS OF AMPHIBIOUS VEHICLE." International Journal of Science, Technology \& Management (2015).

3. Gawande, M., and P. Mali. "Amphibious Vehicle." International Research Journal of Engineering and Technology (IRJET) (2016): 137-138.

4. Hassan, Muhammad Zahir, Muhammad Razil Razali, and Mohd Shazni Halid. "Design and Development of Amphibious Hybrid Vehicle Body Structure." International Journal of Science and Research (IJSR) 2.5 (2013): 220-223.

5. Saidullah Amphibious (http://www.nif.org.in/?q=amphibious_cycle).

6. Shirsath, P. P. S., et al. "A REVIEW ON DESIGN AND ANALYSIS OF AMPHIBIOUS VEHICLE." International Journal of Science, Technology \& Management (2015). Ragi, Shankarachary, et al. "Feasibility study of POMDP in autonomous amphibious vehicle guidance." IFAC Proceedings Volumes 46.10 (2013): 85-90.

7. Sitek, Bart, and Wei Yang. "Conceptual design of an amphibious vehicle: Vector." ARPN J. Eng. Appl. Sci 6.2 (2011): 1-6.

8. Gkikas, Nikolaos. Automotive ergonomics: driver-vehicle interaction. CRC Press, 2016.

9. Frejek, Michael, and Scott Nokleby. "Design of a small-scale autonomous amphibious vehicle." 2008 Canadian Conference on Electrical and Computer Engineering. IEEE, 2008.

10. Bhise, Vivek D. Ergonomics in the automotive design process. CRC Press, 2016.

11. Ritchie, R. O., \& Knott, J. F. (1973). Mechanisms of fatigue crack growth in low alloy steel. Acta Metallurgica, 21(5), 639-648.

12. Garud, R. Y., \& Pandey, A. (2018). Structural Analysis of Automotive Chassis, Design Modification and Optimization. Int. J. Appl. Eng. Res, 13(11), 9887-9892.

13. Dubey, A., \& Dwivedi, V. (2003, December). Vehicle chassis analysis: load cases \& boundary conditions for stress analysis. In 11th National Conference on Machines and Mechanisms. IIT, Delhi, India.

14. Atienza, D. K. D., Bulanadi, E. C. C., Enriquez, M. A. S., Peralta, S M. C., Sabado, A. L. R., Baldovino, R. G., \& Garcia, G. R. (2015, December). Conceptual design of an amphibious E-tricycle. In 2015 International Conference on Humanoid, Nanotechnology, Information Technology, Communication and Control, Environment and Management (HNICEM) (pp. 1-4). IEEE.
15. Baldovino, R. G., \& Garcia, G. R. (2016). Amphibious electric tricycle: Mechanical design, simulation and dynamic analysis. Advanced Science Letters, 22(9), 2141-2144.

16. Wenshan, G. A. O. F. P. A. N. C., and Y. A. N. G. Zheng "Numerical Analysis and Validation of Propeller Open-water Performance Based on CFD [J]." Journal of Mechanical Engineering 8 (2010).

17. Hofheins, Roger W., et al. "Amphibian vehicle." U.S. Patent No. 2,350,037. 30 May 1944.

18. https://www.sciencedirect.com/topics/materials-science/high-strengt h-low-alloy-steel

19. Wilfred, Sessions Donald. "Marine craft including amphibious craft." U.S. Patent No. 3,131,666. 5 May 1964

20. McCauley, J. L. (2018). Hydrodynamic Lift on Boats. arXiv preprint arXiv:1808.03313.

21. Millward, A. (1987). A study of the forces exerted by an oarsman and the effect on boat speed. Journal of sports sciences, 5(2), 93-103.

22. Martin, M. (1978). Theoretical determination of porpoising instability of high-speed planing boats. Journal of ship research, 22(01), 32-53.

23. Cai, W., Chen, L., He, J., \& Huang, G. (2015, June). Establishment and Analysis of a Comprehensive Economic Speed Model for Multi-purpose Marine Working Boats. In The Twenty-fifth International Ocean and Polar Engineering Conference. OnePetro.

24. Wright, B. N. PLEASURE RIDES \& THE AMERICAN DREAM

25. Kalhari, A., Wickramarathna, N., Yapa, L., Nandasena, D., \& Kalansooriya, L. P. (2020). Development of Automated Aquatic Taxi for Sri Lanka using Kansei Engineering Concept.

26. https://www.researchgate.net/figure/Comparison-of-engineering-stre ss-strain-curves-of-HSLA-350-450-and-DP-350-600-steels_fig4_236 886033

\section{AUTHORS PROFILE}

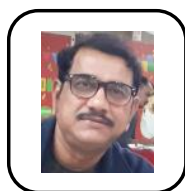

Debashis Majumder, is currently engaged as Professor \& coordinator of Transportation Design in School of Design, UPES, Dehradun. He has a graduate degree in Mechanical Engineering from UCE Burla (1985-89) and has a Master's Degree Program in Industrial Design from National Institute of Design, Ahmedabad, India. He has also studied 'Strategic Management' from IIM, Kashipur in 2017. He has a total of 30 years working experience out of which 25 years in Design, Manufacturing \& R\&D Industry. For last 5 years, he is teaching Transportation Design for Graduate \& Post Graduate (B.Des. \& M.Des. Programs) in Design Colleges in India. He is continuing thesis program from UPES, Dehradun. He has many patents along with Escorts India, TIL India etc. and products has won 'India Design Mark Award' in 2014. His two research papers got best paper award in ICPDIMS and IPDIMS.

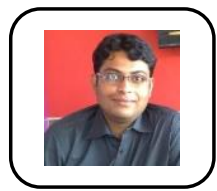

Dr. Anirban Chowdhury, is an author of a book titled "Neurodesign and Neuromarketing Startup Guide". He is a trainer of Design Thinking \& Innovation and Data Analytics. He is an inventor of Non-parametric Mediation Statistics and Transition State Design Economics. He is a practitioner of Value-Based Design Education. He has joined as Faculty and Head of UX \& IxD and R \& D Coordinator to School of Design, University of Petroleum and Energy Studies, Dehradun, on October, 2017. He has worked for MIT Institute of Design, Pune from January, 2015 to September 2017 as an Assistant Professor of User Experience Design. He is an alumnus of the University of Calcutta. He was recently awarded the 'Springer Young Researcher Award-2015 (Doctoral)' given by Indian Society of Ergonomics (ISE) for his research work in the area of cognitive ergonomics and user experience design. He was also awarded the "Young Scientist Award" (2014) by The Physiological Society of India for his Usability Engineering Research. He awarded his $\mathrm{PhD}$ degree from the Indian Institute of Technology (IIT) Guwahati. Area of his $\mathrm{PhD}$ research was Cognitive Ergonomics and Anthropomorphic Product Experience Design. 